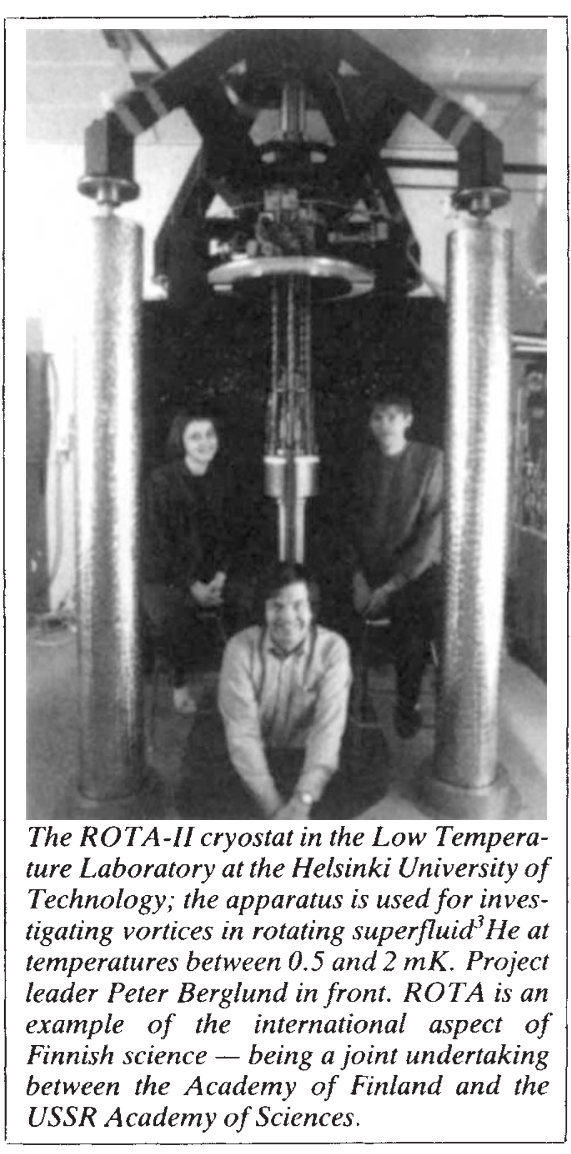

Researcher training

\section{Two doctorates to a PhD?}

THE average Finn is 34 years old when he defends his doctoral dissertation, compared with a mean age of 27 years in the United States and Great Britain. As this threatens to retard Finland's attempts to improve its international competitivity, the Academy of Finland has started to take corrective measures.

The Finnish doctorate is much more than a PhD. Traditionally, both an MSc and the successful submission of a licentiate dissertation (equivalent to two research papers) are required before going on to study for a doctorate. "The threshold of getting a $\mathrm{PhD}$ is too high. It becomes like a final goal", feels Niilo Saranuumi, director of the Medical Engineering Laboratory at the Technical Research Centre of Finland (VTT).

Olli Lounasmaa, research professor at the Low-Temperature Laboratory of the Helsinki University of Technology thinks it is "ridiculous" for a PhD to take 8 years. "The real reason PhDs take so long is that students don't get enough supervision. You need both the carrot and the stick". Lounasmaa's group has produced 31 PhDs since it started in 1965 and he expects 9 more this year.

It is no longer mandatory to submit a

\title{
Regionalization policies in action
}

UNTIL 1917 Finland had only one university, which had been transferred in the nineteenth century from Turku, on the southwest coast, to Helsinki. Now there are nine universities, where most of the country's basic research is carried out, three technical universities and the modern Technical Research Centre of Finland (VTT) at Otaniemi, outside Helsinki, which is the largest technical research campus in the Nordic countries.

The expansion of the university system took place in the 1960s and 70s as part of a government regional development plan, in response to a powerful agro-political lobby. The aim, says Esko-Olavi Seppälä, chief planning officer of the Science and Technology Policy Council of Finland, was to use higher education as a means to stimulate rural areas. "The regional universities have been successful from this point of view", says Seppälä, "but in terms of science policy, they were too small to be effective. The Academy of Finland had to put in a lot of money in the 1980 s, but we are now in a position to concentrate on

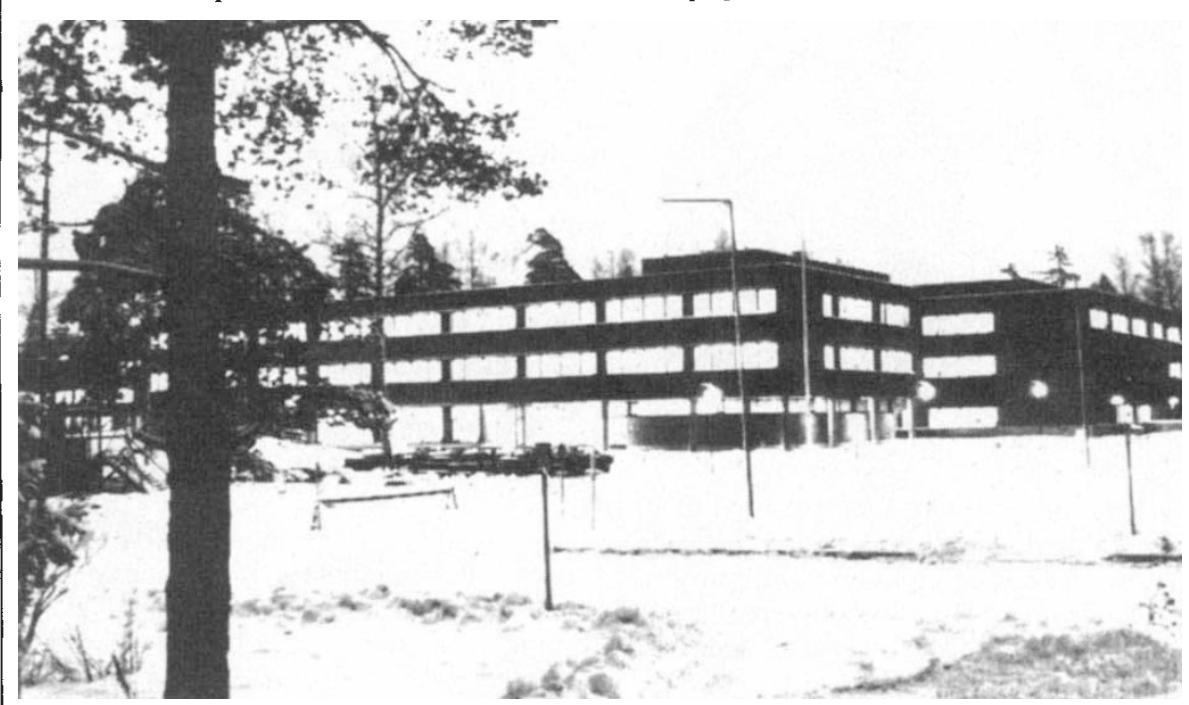

VTT near Helsinki. The largest technology institute in the Nordic countries and a showcase of university-industry collaboration.

licentiate dissertation before starting doctoral work, and more graduate students, as in Lounasmaa's group, are being accepted at MSc level. But in fields such as molecular biology and virology it is not uncommon to find 'double doctors', with both an MD and a PhD, taken one after the other or in parallel. Some, like Kai Krohn, professor of pathology at the University of Tampere, believe this gives Finns an advantage compared with many of their European and American colleagues.

The Academy of Finland has started to tackle the problem of postgraduate training and offers a number of three-year research assistantships, since many of the university assistantships — intended for cience policy, not on walls".

One of the most successful of the regional universities is at Oulu, on the southern edge of Lapland and founded in 1958. Oulu has also recently become the site for the Nordic countries' first science park, with some of Finland's most prominent technology companies, such as electronics firm, Nokia-Mobia Oy.

According to Seppälä, the absence of a regional university system in other Nordic countries, particularly Norway, is casuing "real problems". But it may have disadvantages, too. Kai Simons, Finnish representative at the European Molecular Biology Laboratory at Heidelberg, West Germany, feels that the duplication of resources throughout a country the size of Finland must make it harder to develop world class research groups. "Finland has to make a decision on these universities", says Simons. "The best biomedical group outside Helsinki is at Oulu, but you can't have biological research all over the country. There are five medical schools, for a population of 4.9 million". 